تأثير كاربرد شلتوك برنج و بيوجار آن بر الخوى خيسشدى يك خاك رس سيلتى تحت آبيارى قطرهاى سطحى

افسانه ابراهيمى '*، محمد شايانتزاد' و محمدرضا مصدقى

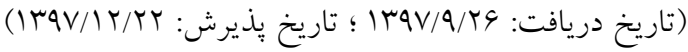

جكيده

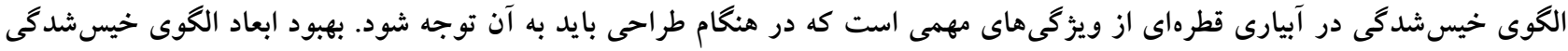

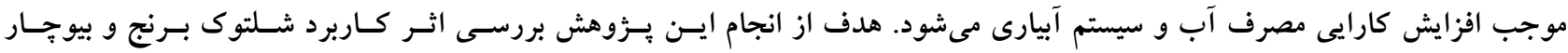
(biochar)

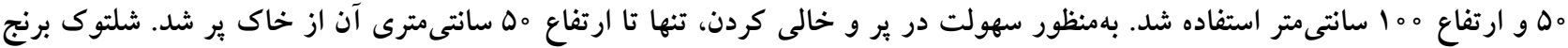

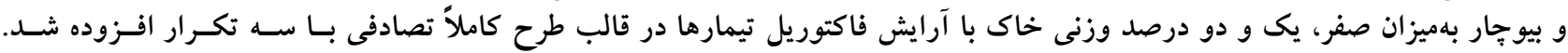

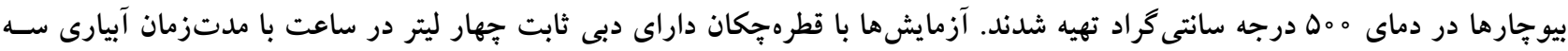

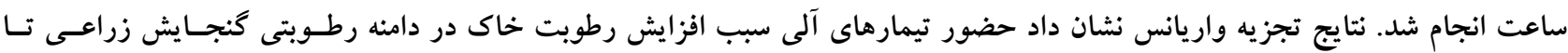

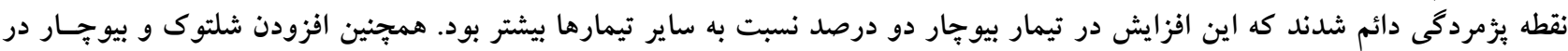

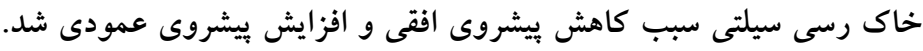

وازههاى كليدى: بيو:جار، شلتوك برنج، آبيارى قطرهاى، جبهه رطوبتى خاك

ا. كروه مهندسى آب، دانشكده كشاورزى، دانشكاه صنعتى اصفهان، ايران

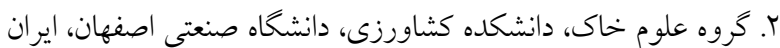
af.ebrahimi@yahoo.com : مسئول مكاتبات: 
افزودنى نظير بقاياى كَاهى، كود دامى، كميوست و مواد بليمرى

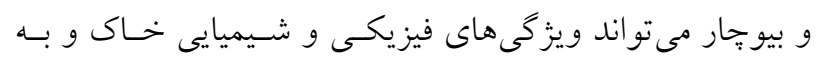

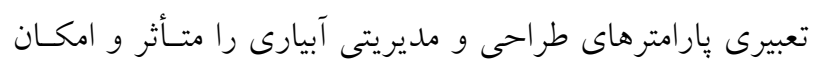
افزايش بهرهورى مصرف آب را فراهم كند. بيو جار زغال تهيهشده از ييروليـز تسوده زيستى (biomass)

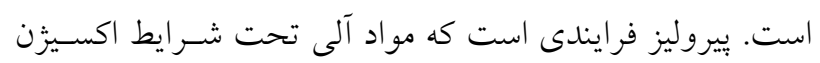

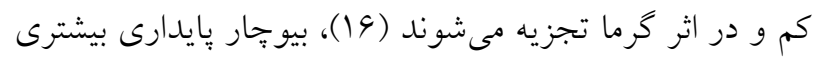

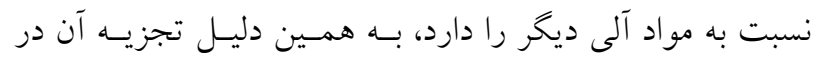

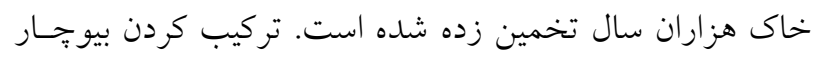

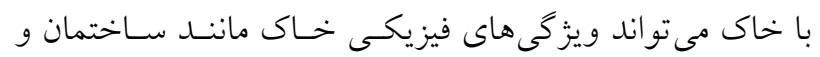

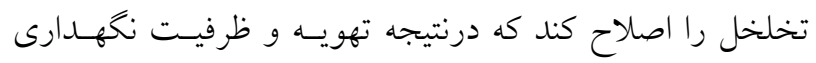
آب خاك، كاركرد خاك و رشد گياهان را بهبود مىبخشد (ه).

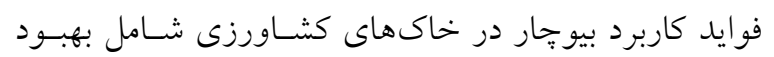

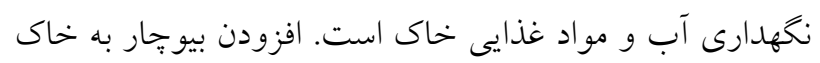

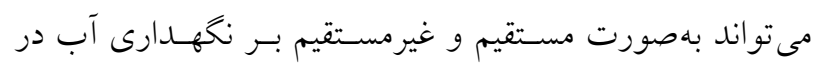

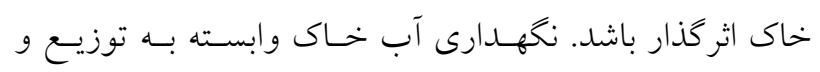

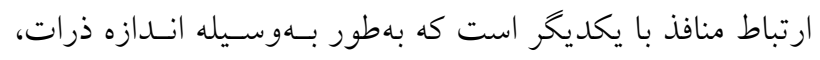

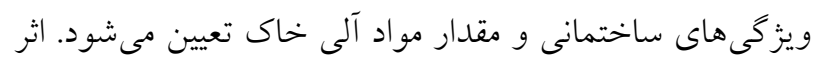

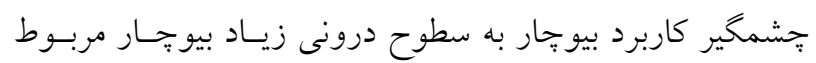

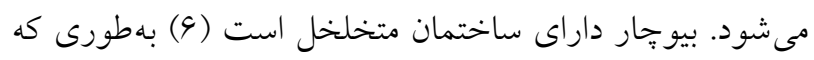

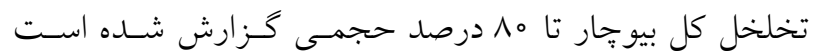
( (ا). بـهدليـل وجـود ايـن سـاختار بسـيار متخلخـل، بيوجــار

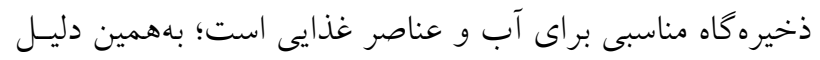
آن را بهعنوان محافظ در برابر خشكى (بهويزه در خـاك شـنى)

$$
\text { در نظر مى گيرند (1) (1). }
$$

افزايش ظرفيت نخهـدارى آب و آب در دسترس (AWC)

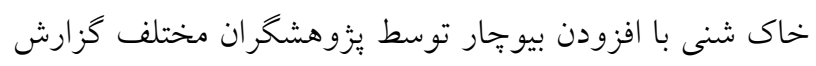

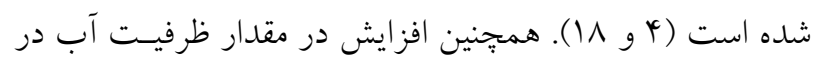

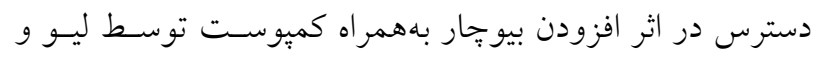

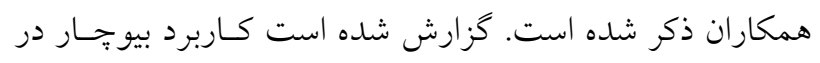

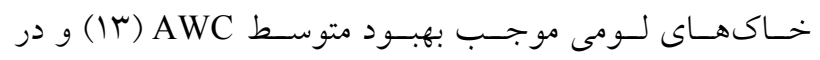
خاكهاى رسى موجب كاهش AWC مى شودو.

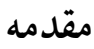

شكل و ابعاد الكوى خيسشدگى مىتواند طراحان را در انتخاب

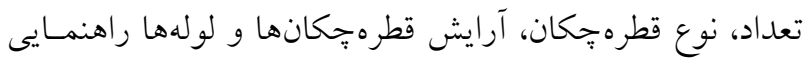

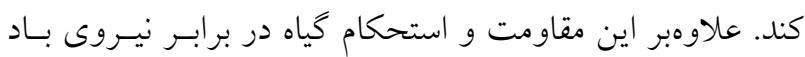

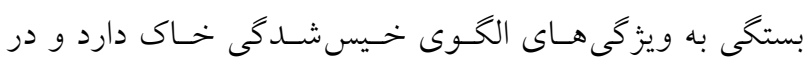

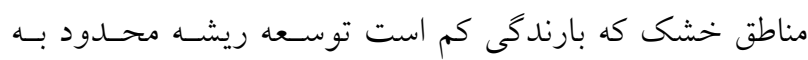

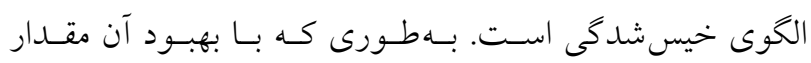

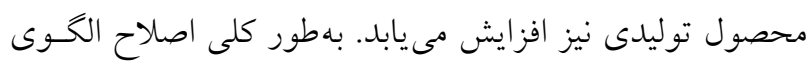

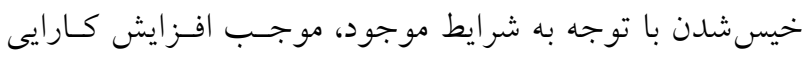

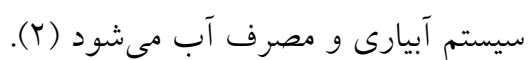

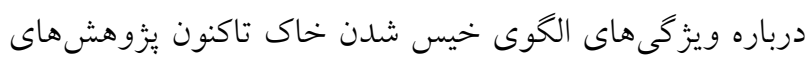
قابل توجهى صـورت پِذيرفتـه اسـت. حيـدرى و همكـاران (9)

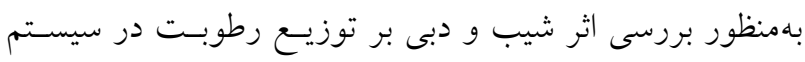

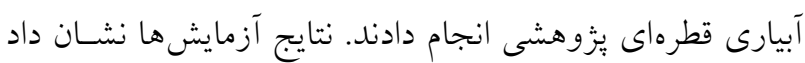

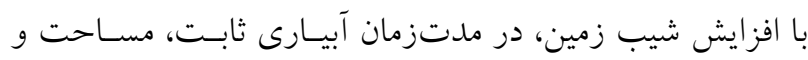

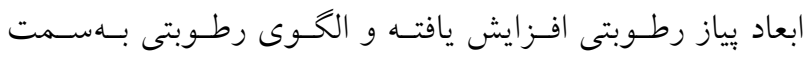

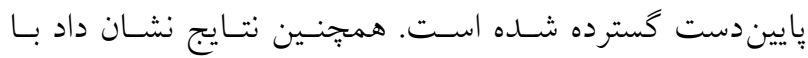
افزايش دبى، مساحت خيسشده افزايش يافت كـهـ بخـش زيـاد

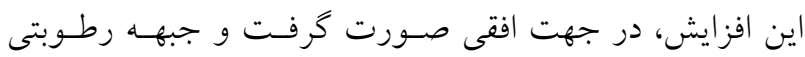
سطحى بود. بهمنظور بررسى اثر حجم آب آبيارى و دبى قطرهجهـان بـر

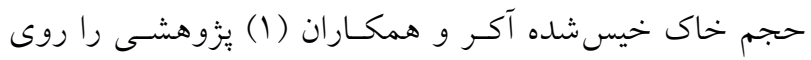

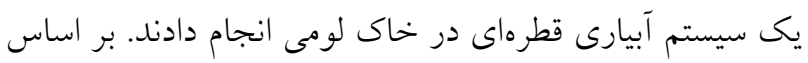

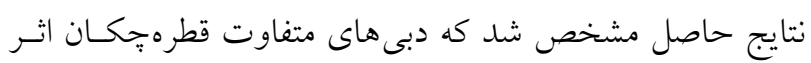

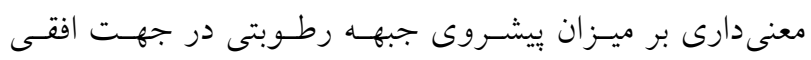

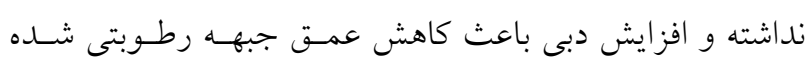

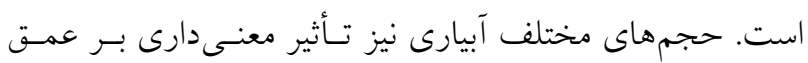

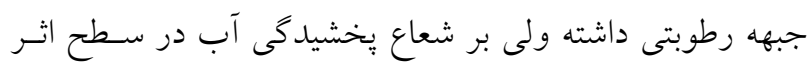

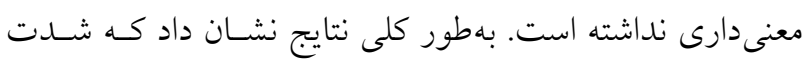
بخش بيشتر آب در سيستم آبيارى قطرهاى باعث كسترش بيشتر

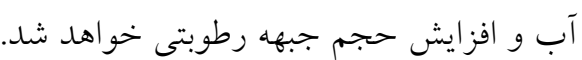

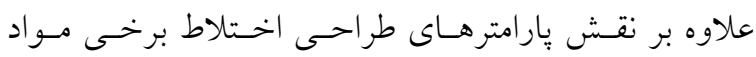


مكعب بود كه در مزرعه به روش اسـتوانه تعيسين شـــ در ايسن

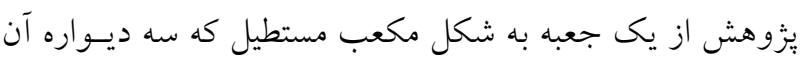

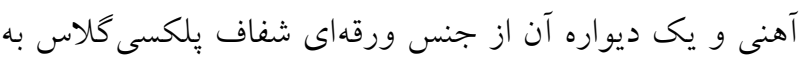

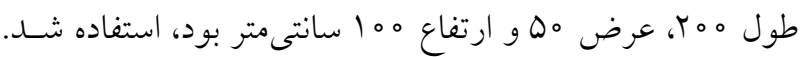

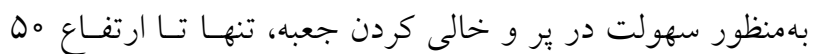

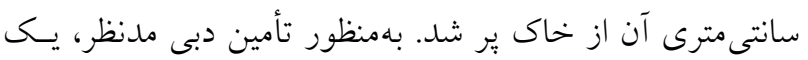

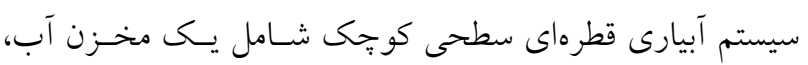
قطرهجان تنظيمشونده و لوله انتقال آب به قطرهجكـان اجـرا و

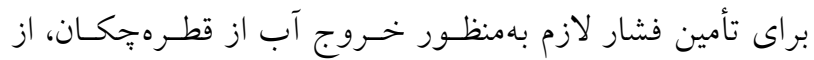

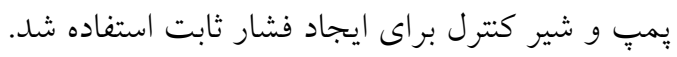
بيوجار مورد استفاده در اين يزوهش از شلتوك برنج بود كه

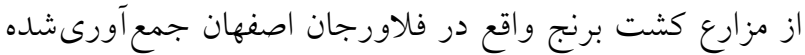

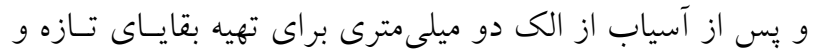

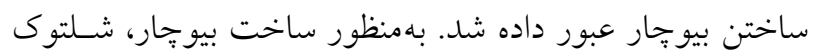

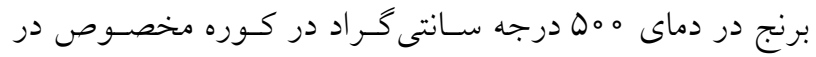

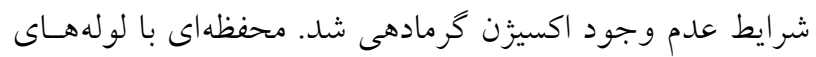
ورودى و خروجى، ترموكويل و مسير جمع آورى شيرابه ساخته

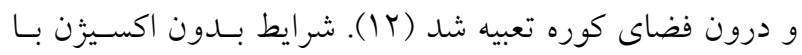

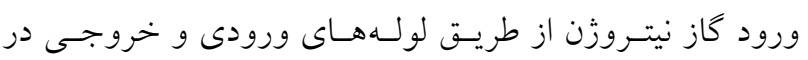

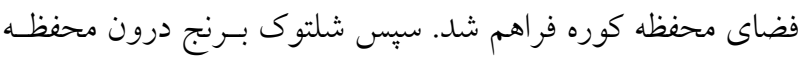

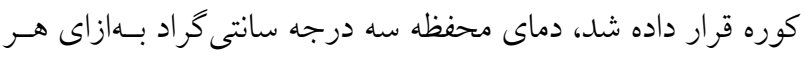

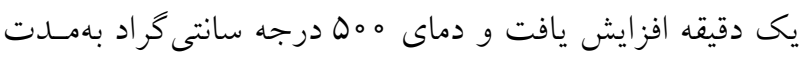

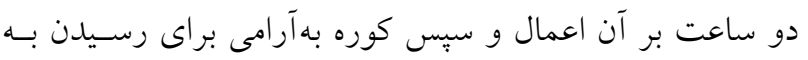

دماى 0 10 درجه سانتى گراد يا كمتر خنكى شد (شكل (1).

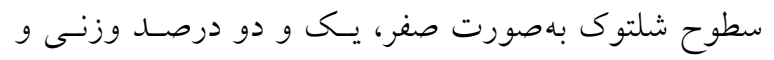
سطوح بيو جار نيز بـهــورت صـفر، يـك و دو درصــ وزنسى

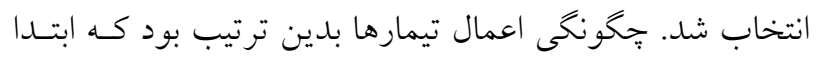

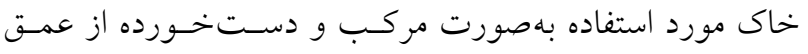

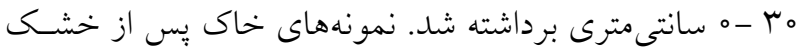

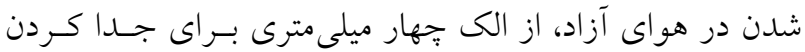

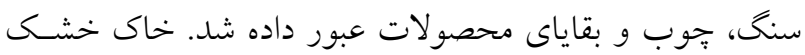
پِ از اختلاط كامل با تيمارها بهصورت دستى به داخـل جعبـهـ
فرامرزى و همكاران (V) در يزوهشى به بررسى تـأثير سطوح

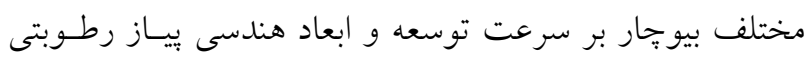
تحت يك تغذيه كننده نقطـهاى در اراضسى شـيبدار برداختنـد.

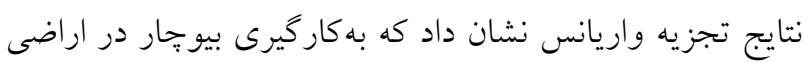
شيبدار مدتزمان توسعه عمقسى جبهـه رطـوبتى را افـزايش داده

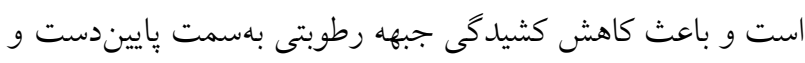
افزايش جبهه رطوبتى بهسمت بالادست كسيلنده بود.

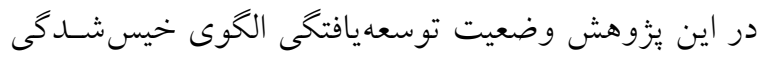

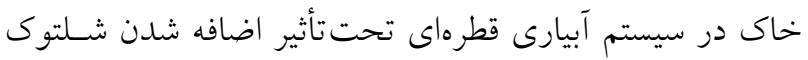

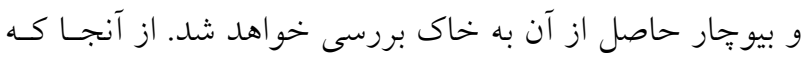

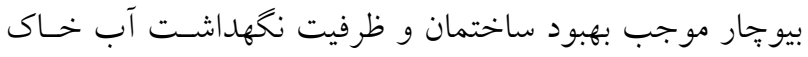

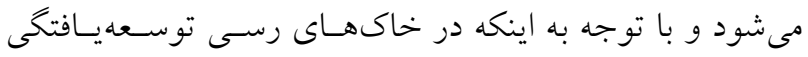

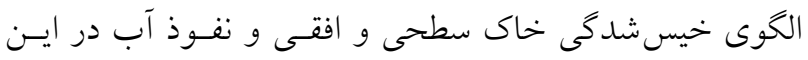
خاكها كمتر است و علاوه بر اينكه مقاومت و استحكام گياه در

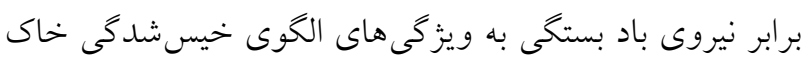

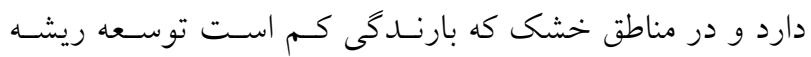
محدود به الكوى خيس شدكى اسـت، بنـابر اين انتظـار مسىرود

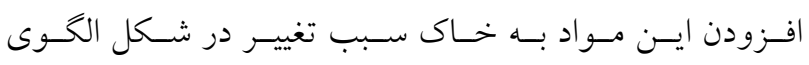
خيسشدى خاك شوند، بههمين دليـل در ايسن بـرزوهش تـأثير

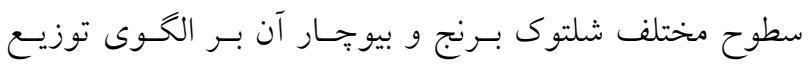
رطوبت خاى تحت آبيارى قطرهاى سطحى بررسى مى شود.

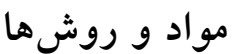

اين يزووهش آزمايشخاهى با كاربرد سه سـطح شـلتوك بـرنج و

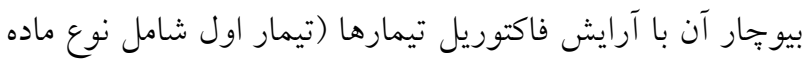

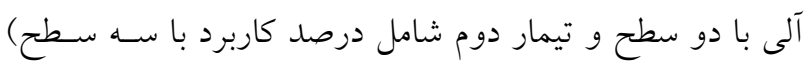

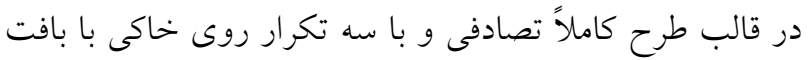

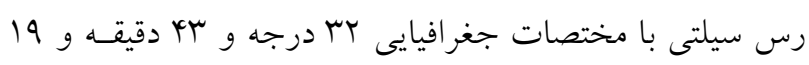

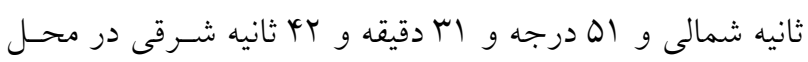

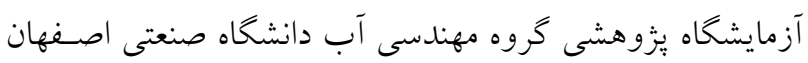

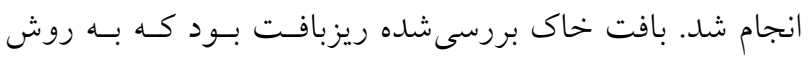

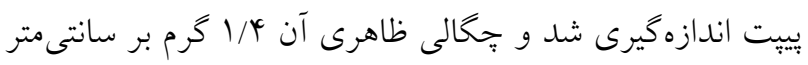




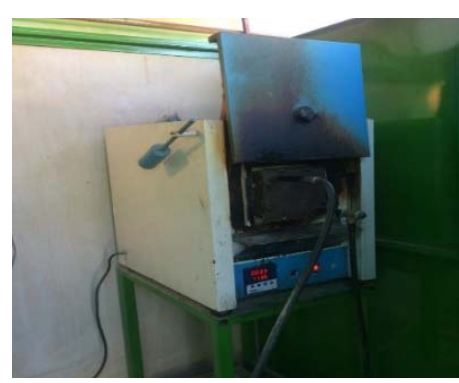

ج

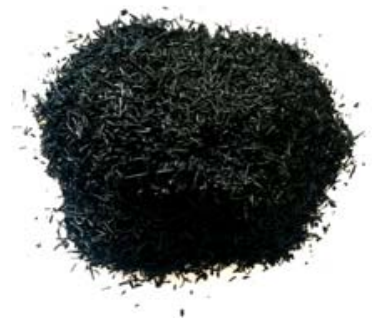

$\underbrace{\varphi}$

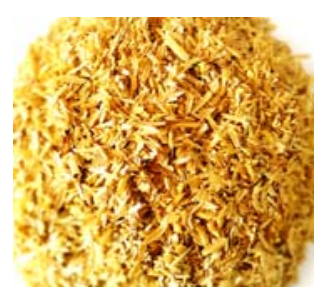

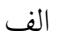

شكل ا. نمايى از: الف) شلتوك برنج آسياب شده، ب) بيوجار توليدشدهو ج) كوره الكتريكى

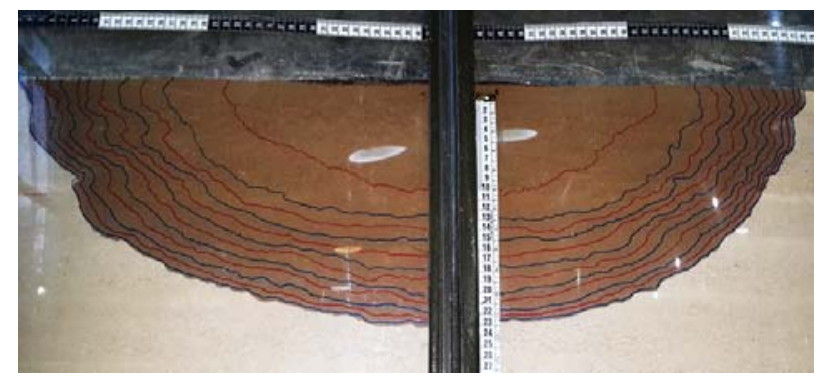

شكل r. نمونهاى از نحوه ترسيم ييشروى رطوبت در خاك

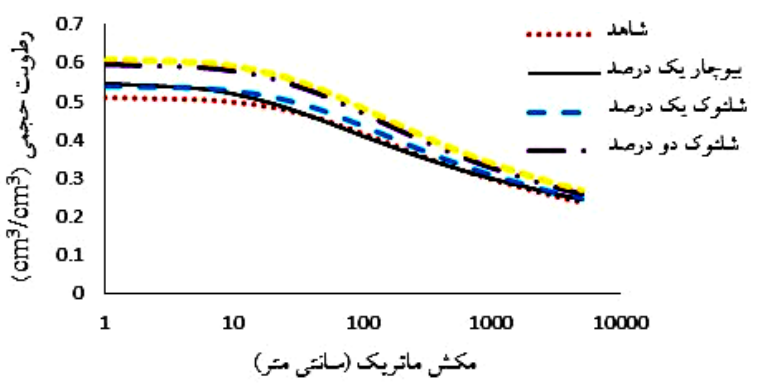

شكل r. منحنى مشخصه رطوبتى خاك رسى سيلتى تحت تأثير دو سطح تيمارهاى بيوجار و شلتوك برنج

يِيشروى (رطوبتى) ترسيم شد. مدت زمان برقـرارى جريـان در

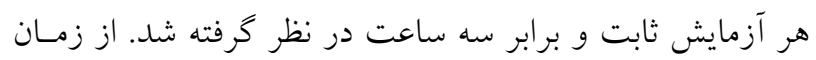

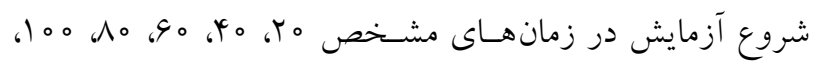

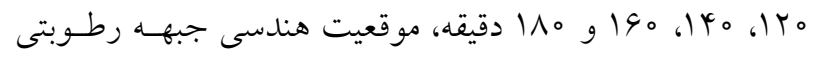

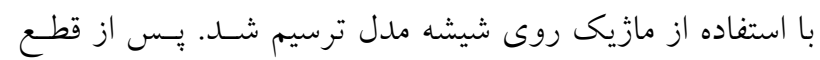

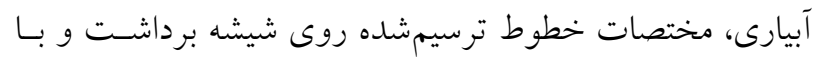

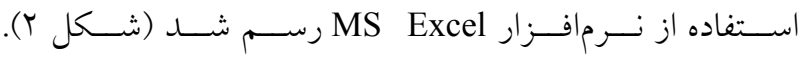

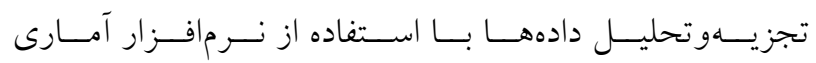
SPSS statistics 23

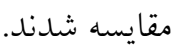

ريخته شده و بهوسيله غلتك به تراكم مــنظر رسـانده شـــ. در

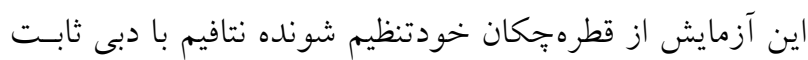

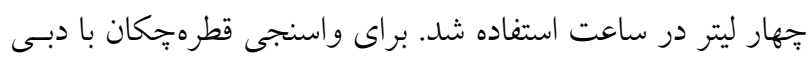
جهار ليتر در ساعت، نيز از بشر مدرج و كرنومتر استفاده شد.

اندازهيرى الكوى خيسشدگى خاى

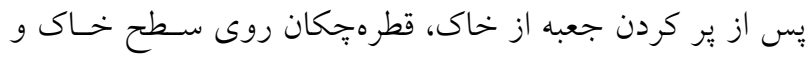

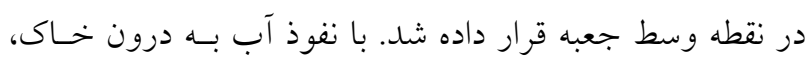

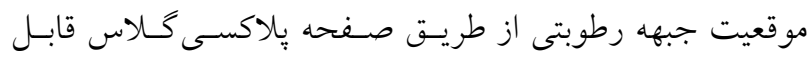

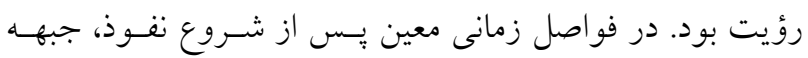


جدول ا. ميانگين بِارامترهاى برازش مدل ونكنوختن براى منحنى نگهداشت آب خاك در خاك رسى سيلتى بهازاى تيمارهاى مختلف

\begin{tabular}{|c|c|c|c|c|c|c|}
\hline $\mathrm{R}^{r}$ & $\mathrm{~m}$ & $\mathrm{n}$ & $\alpha$ & $\theta_{\mathrm{r}}$ & $\theta_{\mathrm{s}}$ & تيمار آلى \\
\hline $0 / 9 \wedge r$ & O/AKO & $1 / T T Q$ & OOYYQ & $0 / T M V$ & $\circ / 0 \circ \Delta$ & شاهد \\
\hline.$/ 9 \wedge 4$ & $\circ / r \circ r$ & I/TOTD &.$/ \% 90$ & OTYQS &.$/ D Y Q$ & خاى حاوى يك درصد بيو:حار \\
\hline $0 / 99$ &.$/ 1990$ & $1 / T Y Q$ & ०/०イ & o/TKY & $0 / D Y \mid$ & خاى حاوى يك درصد شلتوى \\
\hline$\circ / 911$ & $\circ / Y \mid Y$ & $1 / T V Q$ & $\circ / 0 \mu \mathrm{V}$ & $\circ / T \Delta S$ &.$/ 094$ & خاى حاوى دو درصد شلتوى \\
\hline $0 / 919$ & OTYVQ & $1 / 790$ & 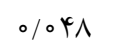 & $0 / T 4 \Lambda$ &.$/ 91 \mathrm{~V}$ & خاى حاوى دو درصد بيوجار \\
\hline
\end{tabular}

مربوط به بارامترهاى هيدروليكى ينج تيمار مورد بررسى ارائسه شده است. افزودن تيمارهاى آلى سبب افزايش رطوبت در نقطه اشباع و بزّمردى خاك در همه مكشها شده است كه بيشترين

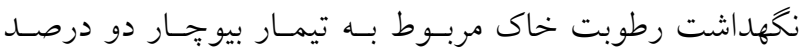

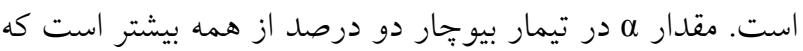

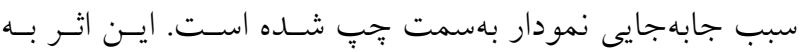

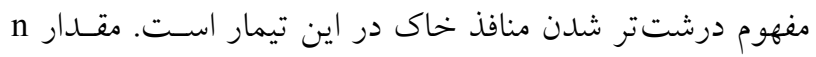
در همه تيمارها روند افزايشى داشته كه بيشترين مقدار متعلق به

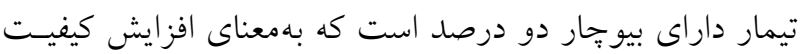

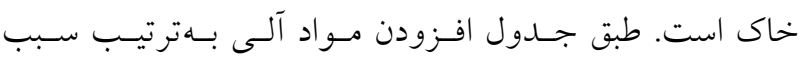

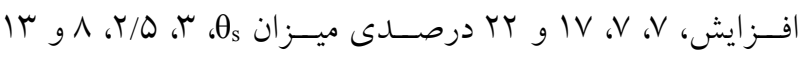
درصدى ميزان

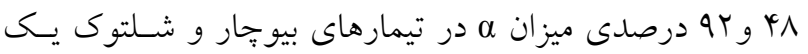
درصد و شلتوك و بيو جار دو درصد نسبت به تيمار شاهد شد.

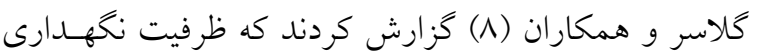

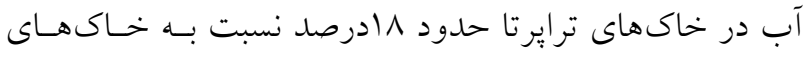
مجاور كه فاقد بيوجار بودند، بيشتر بود. بـا توجـهـ بـه بايــدارى بيو جار در برابر تجزيه، به نظر مىرسد كه ايـن مـاده بـا داشـتن

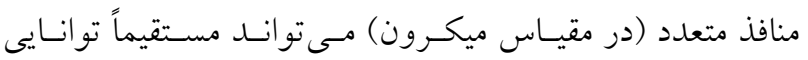
نخهارى آب در خاك را بهصورت بلندمدت افزايش دهد. هينـا

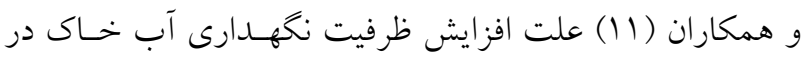
اثر افزودن بيوجار را تخلخـل زيـاد آن و كيشسيموتو و سـوگيرا

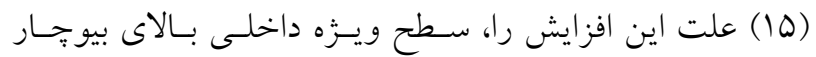

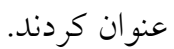
از آنجا كـهـ رفتـار رطـوبتى خـاك در مكششهـاى ماتريـى
از آنجا كه افزودن مواد آلى به خاك سبب تغيير در ويزگگىهـاى

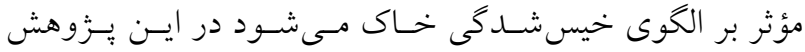
يارامترهاى هيدروليكى تيمارهاى مورد آزمايش توسطط دستخاه

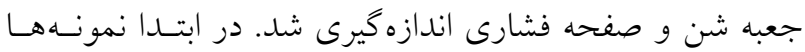

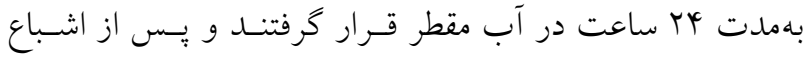

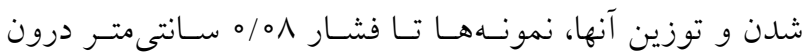
دستخاه جعبه شن و براى سـاير فشـارها درون دسـتخاه صـفحه

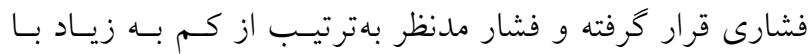

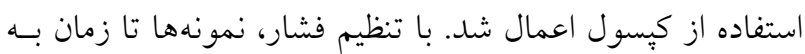

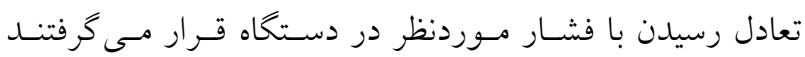
(تا زمانى كه خروج آب از دستخاه مشاهده نشـود) و همجنِنسين

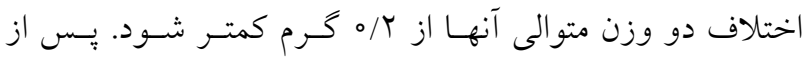

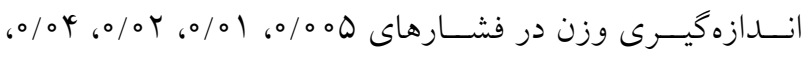

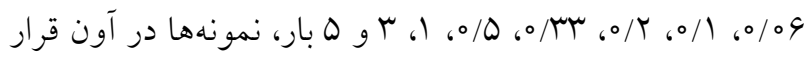

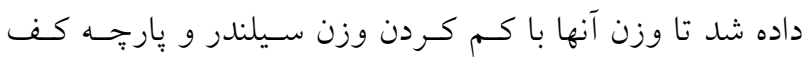

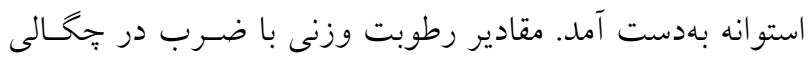

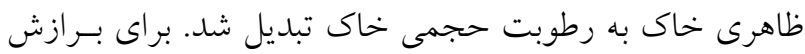
دادهاى منحنى مشخصه رطوبتى نمونههاى خـاك بـا مــدل ون

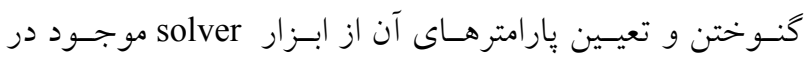
نرم|فزار MS Excel استفاده شد (شكل r).

بحث و نتايج

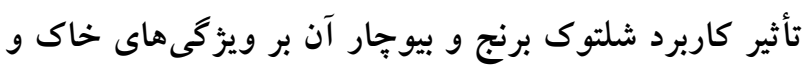
منحنى مشخصه رطوبتى

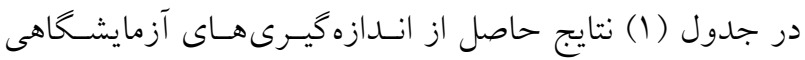




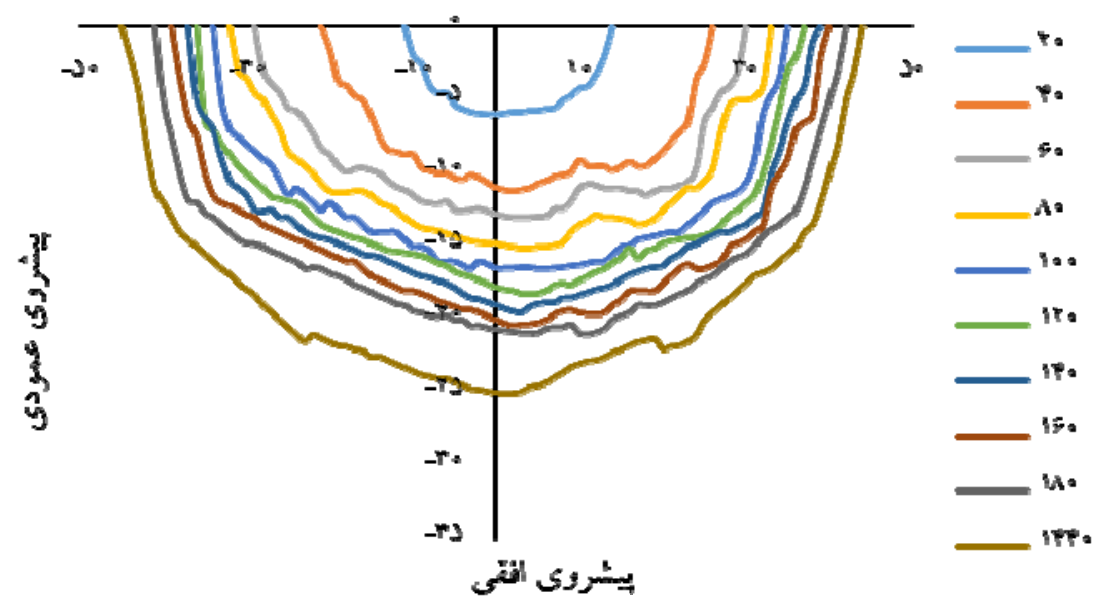

شكل †. بيشروى الكوى خيس شدگى براى خاك شاهد (بدون بيوجار و شلتوك) در زمانهاى مختلف (دقيقه) از شروع آبيارى

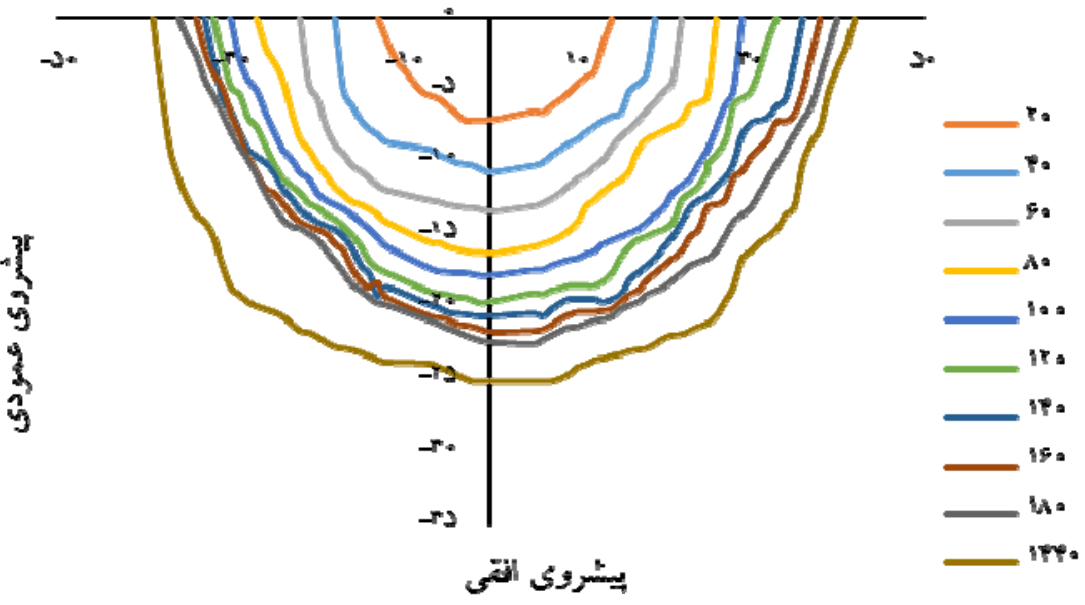

شكل ه. يـشروى الخوى خيس شدىى براى خاك حاوى يك درصد بيوحار در زمانهاى مختلف (دقيقه) پِ إز شروع آبيارى

بالا تحت كنترل بافت خاك و منافذ ريـز آن قـرار دارد ولى در خاك قرار دارد تغييرات معنى دارى نداشته است.

بررسى الخوى خيس شدگى خاى

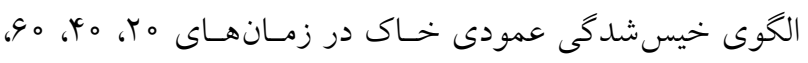

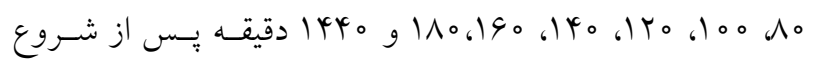
آبيارى در تيمارهاى مختلف در شكل هاى ع تا 1 نشان داده شده

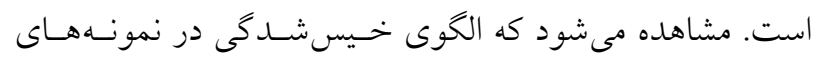
حاوى دو درصد وزنى بيو جار و شلتوى برنج، نسبت به شـاهد

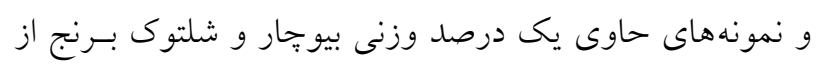

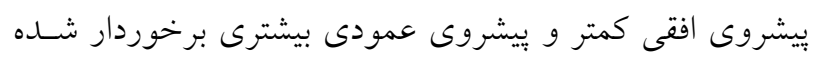
مكشهاى يايين تحت كنترل ساختمان خاك و تخلخل درشـت

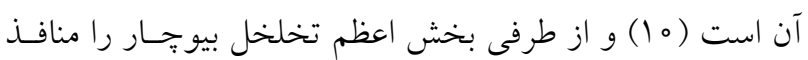

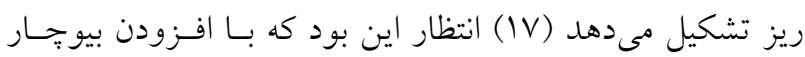

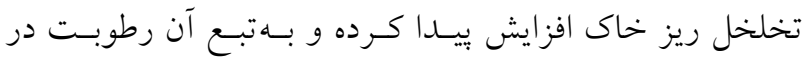

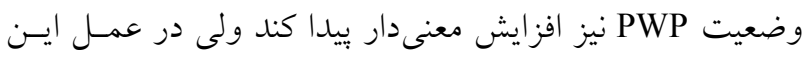

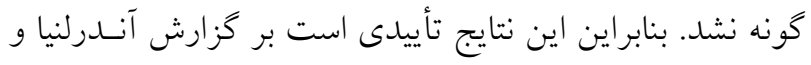

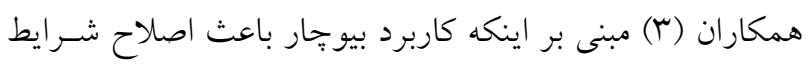

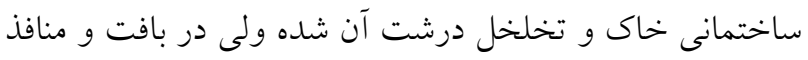

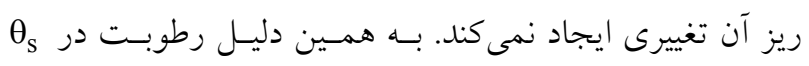

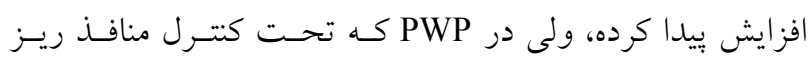




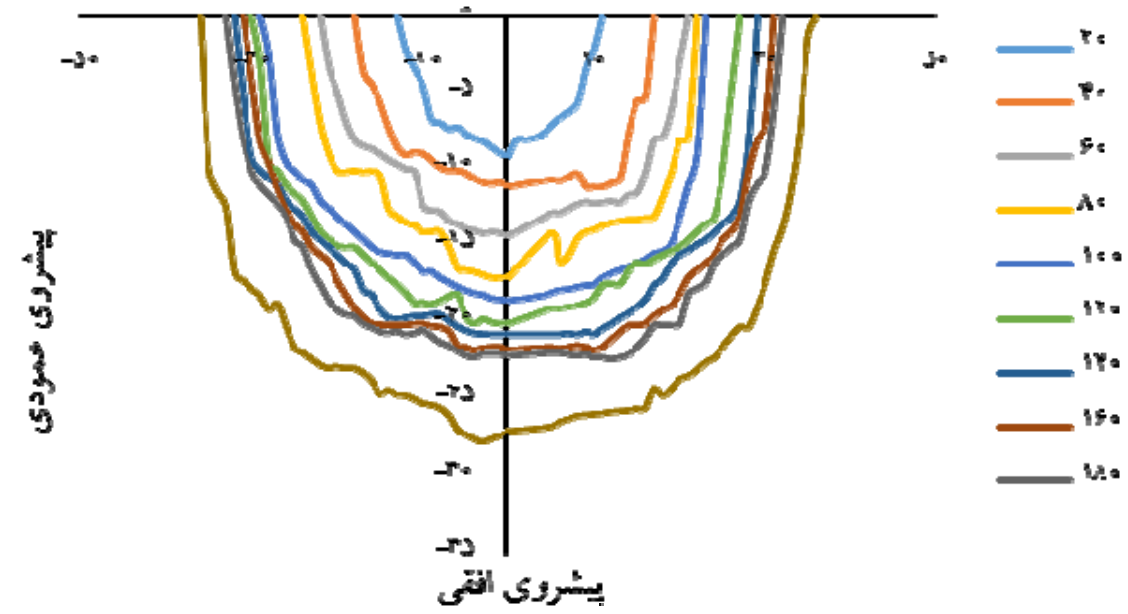

شكل 9. بيشروى الكوى خيس شدى براى خاك حاوى دو درصد بيوجار در زمانهاى مختلف (دقيقه) يِ از شروع آبيارى

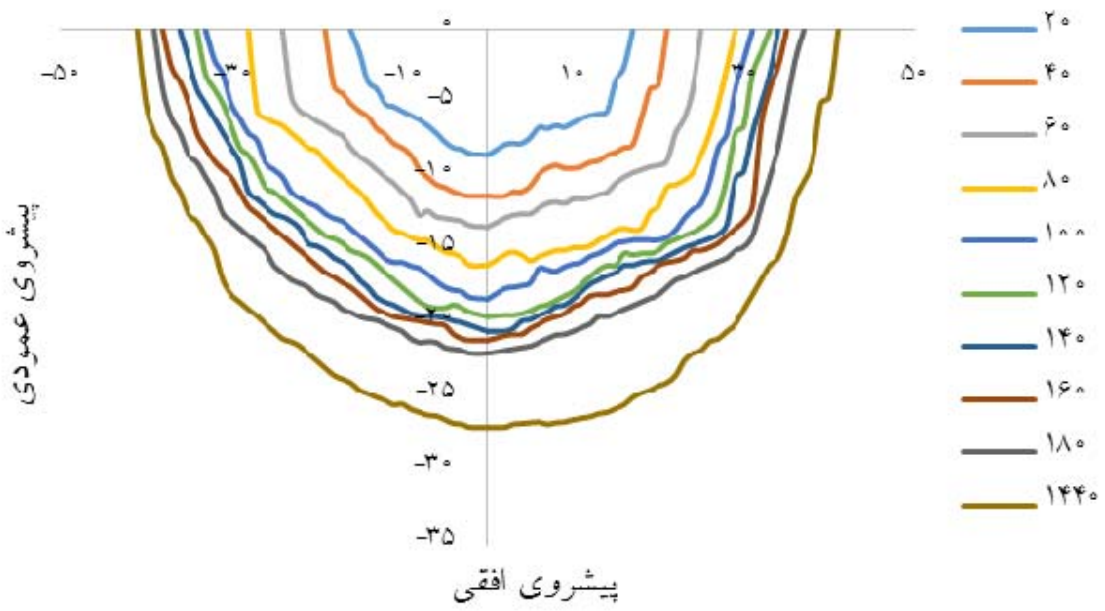

شكل v. ييشروى الكوى خيس شدگى براى خاك حاوى يك درصد شلتوى برنج در زمانهاى مختلف (دقيقه) پِ از شروع آبيارى

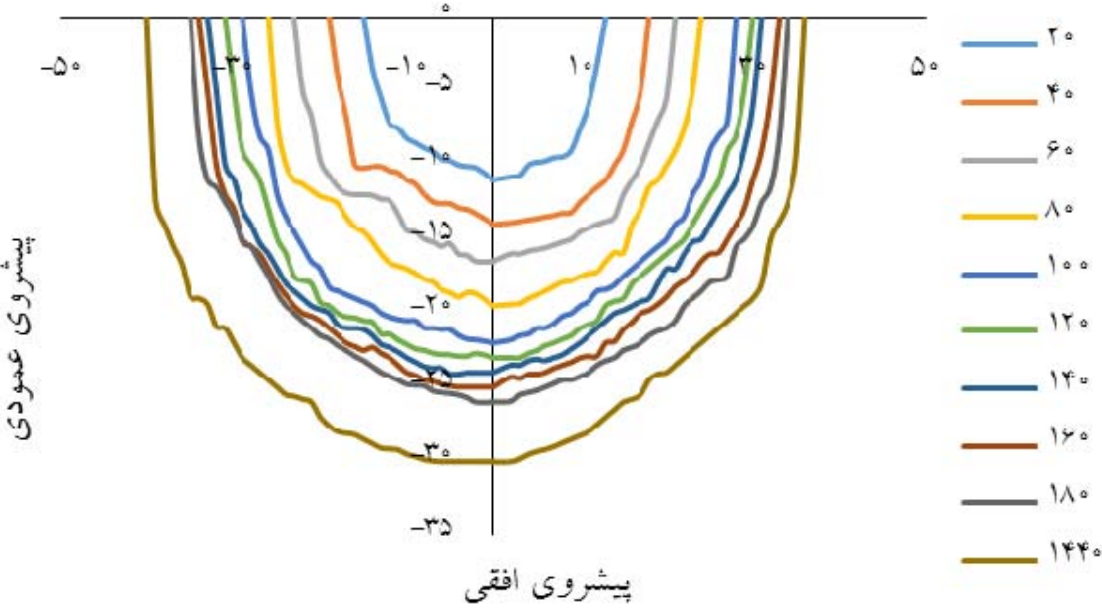

شكل ^^ بيشروى الكوى خيس شدى براى خاى حاوى دو درصد شلتوك در زمانهاى مختلف (دقيقه) بس از شروع آبيارى 
جدول Y. نتايج تجزيه واريانس ميزان بيشروى افقى و عمودى براى جهار زمان ابتدايى، ميانى و انتهايى و YF ساعت پس از آبيارى

\begin{tabular}{|c|c|c|c|c|c|c|c|c|c|}
\hline \multicolumn{4}{|c|}{ بِيشروى افقى (سانتىمتر) } & \multicolumn{4}{|c|}{ بيشروى عمودى (سانتى متر) } & \multirow[t]{2}{*}{ آزادى درجه } & \multirow[t]{2}{*}{ منابع تغييرات } \\
\hline lyto & 110 & 100 & ro & leto & 110 & 100 & ro & & \\
\hline دقيقه & دقيقه & دقيقه & دقيقه & دقيقه & دقيقه & دقيقه & دقيقه & & \\
\hline rG/1ro** & $1 / 94^{*}$ & $\circ / M \wedge q^{n s}$ & ${ }^{\mathrm{ns}}$ & G/AYd** & $r / \notin q Y^{\mathrm{cns}}$ & $1 / 9 Y^{\mathrm{ns}}$ & $\circ / \circ \Delta G \mathrm{~ns}$ & 1 & تيمار \\
\hline 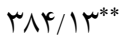 & YYQ/TGY & $k r \circ / \Lambda \wedge q^{* *}$ & $1 \wedge / 0^{* *}$ & YN/IYSO** & $19 / T \& V^{* *}$ & $\mid r / \Delta r^{* *}$ & $10 / Y \wedge r^{* *}$ & r & سطح ماده آلى \\
\hline $\mid r / 9 r D^{* *}$ & $\circ / \Delta 1 Y^{* *}$ & ०/YYYns & $1 / 0^{\mathrm{ns}}$ & $1 / V 4 D^{* *}$ & o/gryns & $\circ / \mathcal{A} Y \mathrm{~ns}$ & $\circ / 0 \varphi)^{\mathrm{ns}}$ & r & سطح × تيمار \\
\hline$\circ / V \Delta$ & $0 / Y \wedge 1$ & $0 / 194$ & $\circ / T Q$ & $\circ / \wedge \vee Q$ & -NAK & $\circ / \mu V D$ & س & ir & خطا \\
\hline
\end{tabular}

*** ** ns: بهترتيب نشاندهنده معنى دارى در سطح احتمال يك درصد، ينج درصد و عدم معنى دارى است.

در هر ستون و هر گروه حروف انخليسى مشترك و غيرمشسترى بهترتيب نشاندهنده عدم تفـاوت معنسى دار و تفـاوت معنسى درار است.

همانطور كـهـ در جــدول r مشـاهده مسىشـود، ازلحـاظ آمارى بين تيمارها تنها در زمان هب دقيقه و بــراى نفـوذ عمقىى تفاوت وجود داشته و براى ساير زمانهـا و همجنــين بيشـروى

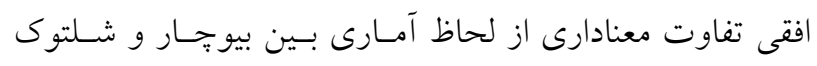
برنج وجود نداشته اسـت. نتـايج مقايسـه ميـانخين و همجنـين شكلهاى با تا 1 نشان مىدهد كه نرخ رشد الخوى خيس شدكى

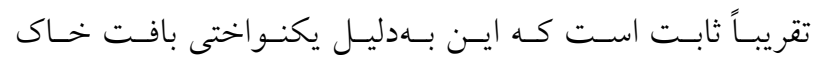

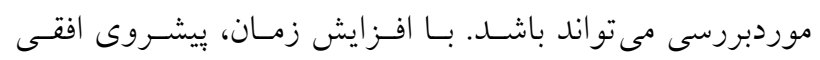
الكوى خيسشدكى خاك كاهش يافت بهطـورى كـه در خـاك بلدون بيو جار و شلتوك، ميزان بيشروى افقسى بلافاصسله يـس از

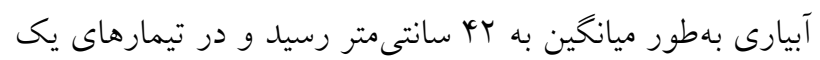

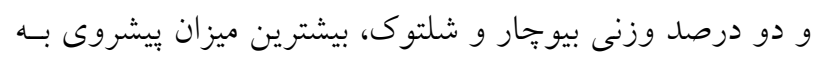

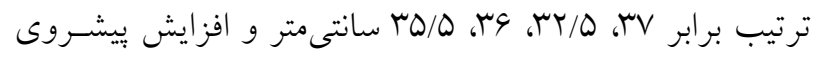

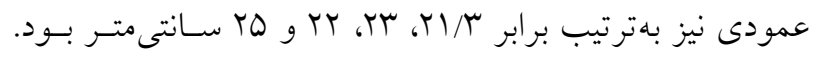
اين نتايج نشان مىدهد كه بيو جار و مواد آلى بـا جـــب آبـ و حفظ آن، كارايى جذب آب خاى را افزايش مىدهند.

\section{نتيجه كيرى}

يافتهاى اين بـرَّوهش نشـان داد كـهـ افـزودن شـلتوك بـرنج و
طبق شكلهاى \ا تا م، كمترين عمـق جبهـه رطـوبتى در تيمـار شاهد بلافاصله يُ از آبيارى تا حدود Yo/V سانتى متر بيشروى كرده است كه با افزايش بيوجار و شلتوك و افزايش سطح آنهـا از يكى به دو درصد ميزان عمق جبهه رطوبتى تا وب سـانتىمتـر براى تيمار شلتوى دو درصد و بr سانتىمتر براى تيمار بيوجار دو درصد افزايش داشته است كه ميزان افزايش در تيمار شلتوك نرخ بيشترى داشت كه مىتوان كفت در تيمـار حساوى بيوجــار، سطح ويزه بـالاى بيو تـار سـبب ذخيـره آب در خــاك شـده و نسبت به تيمار شلتوى دو درصد از بيشـروى عمـودى كمتـرى برخوردار شده و در عوض بيشروى افقى آن بـه نسـبت تيمـار شلتوك دو درصد بيشتر بوده است.

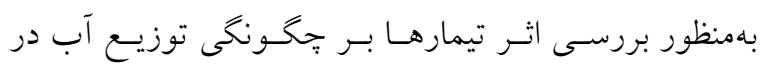

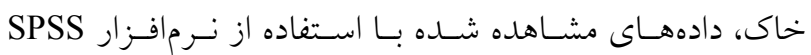
تجزيهوتحليل شد (جدول Y). آناليزهاى انجام شـده، نشـان داد

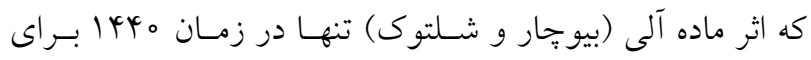

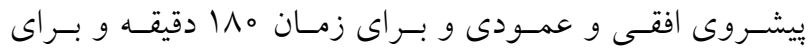
بيشروى افقى معنى دار بود و سطوح ماده آلى نيز براى بيشـروى ليش افقى و عمودى تمام بازههاى زمانى دار ایى اختلاف معنى دار بوده است. از نتايج مقايسه ميانخين (جدول ؟) بين سـطوح مختلـف بيو جار و شلتوك اين نتايج حاصل شد كه بيشروى افقى جبهـهـ رطوبتى بــا افـزايش بيوجــار و مــاده آلى (شـلتوى)، كـاهش و يشيروى عمودى افزايش يافته است. 


\begin{tabular}{|c|c|c|c|c|c|c|c|c|}
\hline \multicolumn{4}{|c|}{ بيشروى افقى (سانتى متر) } & \multicolumn{4}{|c|}{ بيشروى عمودى (سانتى متر) } & \multirow[t]{2}{*}{ تيمارهاى آزمايشى } \\
\hline lkto & 110 & 100 & ro & IYYo & 110 & 100 & ro & \\
\hline \multirow[t]{2}{*}{ دقيقه } & دقيقه & دقيقه & دقيقه & دقيقه & دقيقه & دقيقه & دقيقه & \\
\hline & & & & & & & & نوع تيمار \\
\hline $\mathrm{V} / / 9 \mathrm{Vb}$ & $V T / N^{\mu b}$ & G4/Ma & $r q / 9 V^{a}$ & $r \varphi / /^{b}$ & $r Y / I^{a}$ & $\mathrm{IV} / \mathrm{V}^{\mathrm{a}}$ & $V / r q a$ & بيو پجار \\
\hline \multirow[t]{2}{*}{$\Lambda r / \Delta^{\mathrm{a}}$} & $V N / 1 \varphi^{a}$ & $G \mathcal{Y} / V^{\mathrm{a}}$ & $r q / 9 V^{a}$ & rV/rTa & YY/AYa & $1 \Lambda / \mu^{a}$ & $V / T V^{a}$ & شلتوى برنج \\
\hline & & & & & & & & درصد تيمار آلى \\
\hline $19^{a}$ & $\wedge^{a}$ & $V r^{a}$ & $\mu \mathrm{l} / \mathrm{Q}^{\mathrm{a}}$ & $r \Delta^{b}$ & $Y \circ / V^{c}$ & $19 / 0^{c}$ & $9^{c}$ & صفر \\
\hline$\Lambda 1 / r \Delta^{b}$ & $\vee Q / \circ \wedge^{b}$ & $99 / \pi \mathrm{mb}$ & $r q / r^{\mathrm{ab}}$ & rqb & 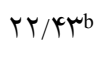 & $1 / /\left.\right|^{b}$ & $\vee / \mu \wedge^{b}$ & يكى \\
\hline \multirow[t]{2}{*}{$v^{\mu c}$} & $G Y / T T^{c}$ & $\Delta \Delta / \mu \mu_{c}$ & $r \Lambda^{c}$ & $r q / 1 Q^{a}$ & $Y Y / Y \Lambda^{\mathrm{a}}$ & $19 / 0^{\mathrm{a}}$ & $N / G Y^{a}$ & دو \\
\hline & & & & & & & & سطح × تيمار \\
\hline $19^{a}$ & $\wedge^{a}$ & - & - & $r Q^{c}$ & - & - & - & شاهد \\
\hline$\Lambda r / \Delta^{b}$ & $V{ }^{c} / \Delta^{b}$ & - & - & $r Q^{c}$ & - & - & - & بيو:جار يك درصد \\
\hline$\Lambda^{\circ} \mathrm{c}$ & $\mathrm{VQ} / 9 \mathrm{~V}^{\mathrm{b}}$ & - & - & $r V^{b c}$ & - & - & - & شلتوى يك درصد \\
\hline$V y^{d}$ & $G Y / 9 V^{c}$ & - & - & $r_{\circ} a$ & - & - & - & شلتوك دو درصد \\
\hline$V \circ e$ & spc & - & - & $r \Lambda / \mu^{b}$ & - & - & - & بيوجار دو درصد \\
\hline
\end{tabular}

در هر ستون و هر كروه حروف انخحليسى مشترى و غيرمشترى به ترتيب نشاندهنده عدم تفاوت معنىدار و تفاوت معنى دار است.

درصدى ميزان پِار امترهاى

شد. بهطور كلسى مسى تـوان كفـت اضـافه كـردن ايسن مـواد بــه

خاكهاى رسى كه ممكن اسـت رشـد ريشـه را محسدود كنتـد،

سبب اصـلاح سـاختمان خهاك، افـزايش نفوذيـذيرى و بهبـود

$$
\text { حركت آب در خاى مىشود. }
$$

$$
\begin{aligned}
& \text { بيوجار به خاك سبب تغيير در الكوى خيس شدكى خـاى شـــ. } \\
& \text { بدينصورت كه با افزودن ايسن مـواد بـه خــاى ييشـروى افقىى } \\
& \text { كاهش و بيشروى عمودى افزايش يافت. همجنين اضافه كـردن } \\
& \text { بيوجار به خاى بهدليل برخوردارى از سطح ويزه زياد و تخلخل } \\
& \text { بالا سبب افزايش يارامترهاى هيدروليكى خاك بهويزه در تيمـار }
\end{aligned}
$$

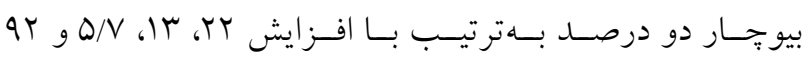

منابع مورد استفاده

1. Acar, B., R. Topak and F. Mikailsoy. 2009. Effect of applied water and discharge rate onwetted soil volume in loam or clay loam soil from an irrigated trickle source. Africa Journal Agricultural Research 1: 49-54.

2. Alizadeh.A. 2004. Principles and Practices of Trickle Irrigation. Astan Quds Razavi Publications, Imam Reza (A.S.) University.

3. Andrenelli, M. C., A. Maienzab, L. Genesiob, F. Migliettab, S. Pellegrini, F. P. Vaccari and N. Vignozzi. 2016. Field application of pelletized biochar: Short-term effect on the hydrological properties of a silty clay loam soil. Agricultural Water Management 163: 190-196.

4. Busscher, W., J. Novak, D. Evans, D. Watts, M. Niandou and M. Ahmedna. 2010. Influence of pecan biochar on physical properties of a norfolk loamy sand. Soil Science 175: 10-14. 
5. Downie, A., A. Crosky and P. Munroe. 2009. Physical properties of biochar. pp. 13-32. In: Lehmann, J. and S. Joseph. (Eds.). Biochar for Environmental Management- Science and Technology Earthscan, London, Sterlin, VA.

6. Downie, A., L. Van Zwieten, W. Doughty and F. Joseph. 2007. Nutrient retention characteristics of chars and the agronomic implication. In: Proceedings of the International Agrichar Iniative Conference, Terrigal, Australia.

7. Faramarzi. E., Nouri. M. R. 2017. Biochar effect on the duration of the penetration depth of wetting front to a specific depth and Wetting Front Advance From emitting the sloping lands. In: Proceeding of the $15^{\text {th }}$ Soil

Science Congress of Iran. Isfahan. Soil Science Society of Iran, Isfahan University of Technology.

8. Glaser, B., J. Lehmann and W. Zech. 2002. Ameliorating physical and chemical properties of highly weathered soils in the tropics with charcoal-a review. Biology and Fertility of Soils 35: 219-230.

9. Heidari. Z., M. Farasati and R. Ghobadian. 2015-2016. Effect OF Slope On Soil Wetting Pattern Under Surface Drip Irrigation And Simulation HYDRUS-2D Model. Journal of Water and Irrigation Management 2: $277-288$.

10. Hillel, D. 1982. Introduction to Soil Physics. Academic Press, New York.

11. Hina, K., P. Bishop, M. C. Arbestain, R. Calvelo-Pereira, J. A. Macia-Agullo, J. Hindmarsh, J. A. Hanly, F. Macias and M. J. Hedley. 2010. Producing biochars with enhanced surface activity through alkaline pretreatment of feedstocks. Australian Journal of Soil Research 48: 606-617.

12. Hossain, M. K., V. Strezov, K. Y. Chan, A. Ziolkowski and P. Nelson. 2011. Influence of pyrolysis temperature on production and nutrientproperties ofwastewater sludge biochar. Journal of Environmental Management 92: 223 -228.

13. Karhu, K., T. Mattila, I. Bergström and K. Regina. 2011. Biochar addition to agricultural soil increased $\mathrm{CH}_{4}$ uptake and water holding capacity results from a short-term pilot field study. Agriculture, Ecosystems and Environment 140: 309-313.

14. Kinney, T., C. Masiello, B. Dugan, W. Hockaday, M. Dean, K. Zygourakis and R. Barnes. 2012. Hydrologic properties of biochars produced at different temperatures. Biomass and Bioenergy 41: 34-43.

15. Kishimoto, S. and G. Sugiura. 1985. Charcoal as a soil conditioner. International Achievements for the Future 5:1223.

16. Lehmann, J. and S. Joseph. 2009. Biochar for Environmental Management: An introduction. pp. 1-13. In: Lehmann, J. and S. Joseph (Eds.). Biochar for Environmental Management. Science Technology. Earthscan, London, UK.

17. Major, J., M. Rondon, D. Molina, S. J. Riha and J. Lehmann. 2010. Maize yield and nutrition during 4 years after biochar application to a Colombian savanna oxisol. Plant Soil 333: 117-128.

18. Novak, J. M., W. J. Busscher, D. L. Laird, M. Ahmedna, D. W. Watts and M. A. S. Niandou. 2009. Impact of biochar amendment on fertility of a southeastern coastal plain soil. Soil Science 174: 105-112 


\title{
The Effect of Rice Husk and its Biochar on Wetting Pattern in a Silty Clay Soil under Surface- Trickle Irrigation
}

\author{
A. Ebrahimi ${ }^{1^{*}}$, M. Shayannejad $^{1}$ and M. R. Mosaddeghi
}

(Received: December 17-2018 ; Accepted: March 13-2019)

\begin{abstract}
Wetting pattern in a trickle irrigation system is one of the most important characteristics that should be taken into consideration for designing the irrigation systems. Improving the dimensions of the wetting pattern will increase the water use efficiency and irrigation systems. The objective of this study was to investigate the effect of rice husk and its biochar application on the wetting pattern in a silty clay soil under surface trickle irrigation. A box with the length of 200, the width of 50 and the height of $100 \mathrm{~cm}$ was used. To easily fill and empty the model, it was filled up to a height of $50 \mathrm{~cm}$. The rice husk and its biochar were added to the soil at the rates of 0,1 and 2 mass percentages based on a factorial arrangement of the treatments in a completely randomized design with three replications. Biochar was prepared in a special furnace at $500^{\circ} \mathrm{C}$ without oxygen. The experiments were done with a flow rate of 4 liters per hour with the irrigation time of 3 hours. The results of the analysis of variance showed that the organic treatments increased the soil water content in the range of field capacity to a permanent wilting point; the highest increase was observed for the biochar $2 \%$ treated soil. Also, the addition of rice husk and biochar in the silty clay soil reduced the horizontal advance and increased the vertical advance wetting pattern.
\end{abstract}

Keywords: Biochar, Rice husk, Surface trickle irrigation, Wetting pattern

1. Department of Water Engineering, College of Agriculture, Isfahan University of Technology, Isfahan, Iran.

2. Department of Soil Science, College of Agriculture, Isfahan University of Technology, Isfahan, Iran.

*: Corresponding author: af.ebrahimi@yahoo.com 